\title{
“FLASHES" DE COMO AS GESTANTES PERCEBEM A ASSISTÊNCIA PRÉ-NATAL EM UM HOSPITAL UNIVERSITÁRIO
}

MARCON, S.S. "Flashes" de como as gestantes percebem a assistência pré-natal em um hospital universitário.

Rev.latino-am.enfermagem, Ribeirão Preto, v. 5, n. 4, p. 43-54, outubro 1997.

Este artigo foi extraído de um estudo desenvolvido com o objetivo de compreender e caracterizar a assistência pré-natal prestada à gestante no ambulatório de um hospital universitário (MARCON, 1990). Trata-se de um estudo qualitativo que adotou como linha metodológica básica a etnografia, mais especificamente a minietnografia, e como método de coleta de dados a observação-participante. Os resultados demonstraram que, ao se relacionarem com profissionais de saúde, as gestantes filtram informações ao mesmo tempo em que se apresentam como clientes não-participativas, uma vez que não questionam a assistência que lhes é prestada, mesmo quando esta não atende às suas expectativas. Além disso, apesar de as mulheres considerarem que a assistência prestada no serviço em estudo é melhor do que a prestada em outros serviços, ela não consegue, segundo as próprias gestantes, atender às suas expectativas e necessidades reais. De forma geral, elas gostariam de receber mais orientações e uma assistência menos impessoal. Os motivos que as levam a não gostar muito da assistência estão relacionados principalmente com a rotatividade dos alunos.

UNITERMOS: assistência pré-natal, hospital universitário, avaliação do serviço pela cliente

\section{INTRODUÇÃO}

Embora o acompanhamento pré-natal já tenha provado sua eficácia na assistência da mãe e do concepto, no que diz respeito às taxas de morbi-mortalidade (CORTEGUERA et al., 1976; ADRIAZOLA et al., 1987; BELIZÁN et al., 1979), ainda apresenta deficiências tanto na extensão da cobertura como no padrão de qualidade.

Por outro lado, a despeito da eficácia dos programas de assistência pré-natal, constatei que desde que estes programas começaram a ser implantados nos mais diversos pontos do País, concomitantemente passou a existir, por parte dos profissionais envolvidos, uma preocupação com sua parcela quantificável: cobertura do serviço com relação à população estimada de gestantes, número médio de consultas por gestantes, época do início do acompanhamento pré-natal, número de exames realizados, cobertura vacinal, etc. (CIARI et al., 1972; LESSA et al., 1976; PAIM et al., 1976; BELIZÁN et al., 1979; CANDEIAS, 1980), bem como a influência destes aspectos no desfecho da gravidez.

$\mathrm{Na}$ área de enfermagem, a avaliação tem sido feita com relação à eficácia das orientações realizadas durante o pré-natal quanto ao preparo psicoprofilático para o parto (ALMEIDA, 1972; FREDDI, 1973; PELÁ, 1979), com relação às orientações sobre o aleitamento materno e sua prática no puerpério (SILVA, 1988), sobre os tipos de orientações que são fornecidas de acordo com o período de gravidez e as que deveriam ter sido dadas, e as que são anotadas no prontuário (ÉVORA, 1988). Isto demonstra que, no âmbito da avaliação da assistência de enfermagem à gestante, muito ainda se tem por fazer, mesmo com relação aos aspectos quantificáveis.

Como regra geral, observei que nos estudos onde a prestação de assistência às gestantes foi investigada, não se procurou valorizar a perspectiva e a percepção das mulheres, embora estas constituam, junto com seus filhos, a razão da existência destes serviços. Aliás, perspectivas, percepções e sentimentos de gestantes são muito pouco valorizados em estudos nacionais. $\mathrm{Na}$ ocasião do desenvolvimento do estudo que originou este texto, trabalhos desta natureza eram escassos (e ainda continuam sendo) e versavam somente sobre alguns aspectos (EIRAS, 1983; NASCIMENTO, 1984; GARCIA, 1985), entre os quais, não se inclui a assistência recebida durante o pré-natal. Este aspecto não foi abordado nem mesmo no estudo de MARCON (1989), embora o mesmo englobe, a partir da percepção das próprias gestantes, toda a experiência vivida por uma mulher durante o período gestacional.

* Professora Adjunta da Universidade Estadual de Maringá - PR. Professora Livre-Docente de Enfermagem em Saúde Pública. Doutoranda em Filosofia da Enfermagem, na UFSC. 
Foi a percepção dessa lacuna que motivou o desenvolvimento do estudo em questão, e mais tarde, o de BONADIO (1996), visto que mesmo no âmbito internacional, onde já existem muitos estudos de caráter mais abrangente, e que foram realizados a partir da perspectiva de gestantes, o enfoque ainda é fragmentado (mudança na auto-imagem, no relacionamento conjugal, no relacionamento com filhos e familiares e o suporte social recebido durante a gravidez) e a assistência prénatal recebida não tem sido abordada.

Este tipo de avaliação, baseada na perspectiva das próprias usuárias, embora limitada à assistência prestada em determinado serviço, se mostra necessária por que os tipos de estudos que estão sendo realizados sobre a assistência pré-natal não têm conseguido produzir, de modo significativo, uma melhoria na qualidade da assistência prestada pelos profissionais da área, nestes serviços. Talvez porque a análise quantitativa da utilização dos serviços de saúde, de modo geral, tenha se restringido aos aspectos da produção do serviço (número de inscritos e de consultas realizadas, época do início do acompanhamento, atividades desenvolvidas entre outros). É que este enfoque revela dados referentes a apenas uma parte dos problemas existentes (CIARI, 1972), pois não indica como e por que a população que utiliza tais serviços o faz, assim como não identifica as características da população que não comparece aos serviços, os motivos do não comparecimento, ou mesmo certas mudanças de atitudes, como por exemplo, o abandono do programa.

Além disso, corroboro a afirmação de BELIZÁN et al. (1979, p.121) de que a atenção que se oferece nestes serviços nem sempre responde às necessidades e expectativas sentidas pelas gestantes, e isto acontece possivelmente porque estes se organizam de forma alheia aos padrões culturais da população a que se destina.

Assim, a despeito dos inúmeros estudos já realizados tendo como foco central a avaliação dos serviços prestados, o que se observa ainda hoje é que os resultados destes estudos não foram capazes de produzir uma mudança significativa na prestação dos serviços e mesmo na adesão das clientes aos seus programas, o que caracteriza um desencontro entre o que é oferecido e o que as clientes desejam. Para que este tipo de problema seja solucionado, é preciso que se dê início a uma nova forma de avaliação ou caracterização do que é oferecido, e nesta, a perspectiva, a percepção e a experiência vivida pelas mulheres grávidas dentro destes serviços têm de ser valorizadas, além é claro, de passar a compreender o período de gestação enquanto um fenômeno experienciado pelo ser humano de forma particular e individualizada. Foi dentro deste contexto que surgiu o interesse em estudar a assistência que tem sido prestada à mulher em estado gestacional em um hospital universitário, a partir de várias perspectivas (da gestante, dos estudantes de medicina, da enfermeira) e de maneira tal que contribuísse no conhecimento do que pode interferir na sua forma de ser.

O objetivo deste artigo, portanto, é apresentar aspectos da percepção das gestantes sobre a assistência pré-natal recebida no ambulatório de um hospital universitário.

\section{APRESENTANDO O ESTUDO}

Este artigo foi extraído de um estudo mais amplo que objetivou explorar, compreender e caracterizar alguns aspectos da assistência pré-natal em um hospital universitário (MARCON, 1990) e que foi desenvolvido a partir da análise secundária de parte dos dados utilizados na construção da teoria substantiva em desenvolvimento denominada "Vivenciando a gravidez" (MARCON, 1989).

A pesquisa é do tipo qualitativo e adotou como linha metodológica básica os pressupostos da etnografia, mais especificamente a minietnografia, conforme o modelo proposto por LEININGER (1985).

Os dados analisados neste trabalho foram coletados no período de outubro de 1986 a julho de 1987 , diariamente e no mesmo dia e local em que a assistência era prestada (ambulatório de ginecologia e obstetrícia). Como método de coleta de dados foi adotado o da observação participante (LEININGER, 1985). O papel adotado durante a coleta de dados foi o de observadora e participante (PEARSALL, 1965), sendo que minha participação foi do tipo "conhecida" (LOFLAND, 1971). As técnicas utilizadas na coleta de dados foram a observação, a consulta a documentos (prontuários das gestantes) e entrevista.

As entrevistas, no início, foram bem abertas pois o objetivo era explorar e apreender num sentido mais geral, com o decorrer do tempo, à medida que os dados eram analisados e o modelo teórico começava a ser esboçado, elas foram se tornando cada vez mais estruturadas, a fim de permitir o esclarecimento de dúvidas e a confirmação ou rejeição de hipóteses.

A gestante foi acompanhada/observada em toda a sua trajetória no serviço, desde a chegada, a espera para ser atendida, os procedimentos realizados (recepção, préconsulta, consulta médica e pós-consulta) até o momento em que eram feitas as entrevistas por mim. Os documentos consultados foram seus prontuários e a entrevista, por sua vez, era aberta, partindo sempre de uma pergunta geral do tipo: "Como você está desde a última vez em que conversamos"? Ou então de uma solicitação para detalhar algum aspecto observado ou ouvido durante quaisquer dos atendimentos. 
A amostra deste estudo foi formada por dois grupos de participantes: o pessoal do serviço e as gestantes. O grupo de gestantes foi constituído de 58 mulheres, selecionadas de acordo com a ordem de chegada no serviço, ou seja, no primeiro mês destinado à coleta de dados, a primeira e a última gestante a chegarem (independentemente de qualquer outra característica) foram informadas sobre o estudo e convidadas a participar do mesmo. Aquelas que verbalmente concordaram ou demonstraram interesse em participar, nos meses subsequentes foram acompanhadas, observadas e entrevistadas em todos os retornos ao serviço, sendo que, com a maioria das gestantes foi mantida uma média de 4 a 5 encontros; com oito delas foi mantido um único encontro e, com algumas, estes foram em torno de 7 a 10.

Na ocasião da coleta de dados, a assistência prénatal no serviço era prestada por acadêmicos da $11^{\mathrm{a}}$ fase do curso de Medicina (doutorandos), que atuavam sempre em dupla e sob a supervisão de dois docentes, os quais eram responsáveis tanto pelos atendimentos da obstetrícia como da ginecologia.

$\mathrm{O}$ atendimento obstétrico era realizado só no período matutino, podendo ser agendadas diariamente seis consultas à gestante sadia, devendo ser quatro retornos e duas novas consultas. $\mathrm{O}$ atendimento à gestante de alto risco era feito só às quintas-feiras (com um outro docente) e não existia um número rígido de consultas por dia, sendo que o número diário variava entre 10 e 12 consultas.

\section{TRABALHANDO OS DADOS COLETADOS}

Na análise dos dados utilizei o método de análise etnográfica preconizado por SPRADLEY (1979) e PARSE et al. (1985). Este método envolve a procura pelas partes de uma cultura, a relação entre estas partes e a relação das partes com o todo. Ele inclui quatro níveis de análise que se desenvolvem numa espiral de complexidade crescente e não em um contínuo linear. São eles: análise de domínios, taxonômica, componencial e temática, além da identificação de proposições hipotéticas. À medida que se sobe na espiral, através dos vários níveis, novas dimensões de compreensão são descobertas e novas questões emergem, expandindo-se e dando sentido aos resultados.

De acordo com o modelo de análise adotado, os domínios surgiram já no primeiro nível de análise: inicialmente foi feito um agrupamento das informações obtidas (dados brutos), dando origem a vários grupos de categorias e subcategorias. Através da reunião destas, chegou-se à identificação de vários domínios, tendo-se optado por aprofundar a análise somente daqueles relacionados diretamente com a assistência pré-natal, o que totalizou 11 domínios relativos às gestantes, 6 relativos à enfermeira e 8 relativos aos médicos. Neste artigo somente serão apresentados os domínios relativos às gestantes.

\section{RESULTADOS}

No Quadro 1 são apresentados os domínios relativos às gestantes selecionados para estudo. Fizeram parte do estudo 58 gestantes, sendo que destas, 36 eram casadas, sete eram solteiras e 15 eram solteiras, mas com a gravidez passaram a morar junto com o companheiro. Menos de $50 \%$ das gestantes (25) iniciaram o pré-natal no primeiro trimestre, e em torno de $40 \%$, só no terceiro trimestre. $\mathrm{O}$ grupo de gestantes que iniciou, em maior proporção, o acompanhamento de seu pré-natal no segundo trimestre foi o de gestantes que permaneceram solteiras, apesar da gravidez (75\%). Sete gestantes tinham menos de vinte anos, quarenta e sete $(81 \%)$ tinham entre 20 e 34 anos e quatro $(6,9 \%)$ tinham mais de 35 anos.

Levando-se em conta o número de filhos, $50 \%$ das gestantes eram primigestas, $22,4 \%$ eram secundigestas, $17,2 \%$ estavam grávidas pela terceira ou quarta vez e $10,3 \%$ eram grandes multíparas. Chamoume a atenção o fato de $50 \%$ das primigestas terem iniciado o pré-natal no segundo trimestre e $21,4 \%$ só no terceiro trimestre. Se estivesse em estudo a questão da qualidade do serviço, esta certamente seria influenciada pelo início tardio de acompanhamento da gestação. Neste grupo, como veremos adiante, o principal motivo para iniciarem tardiamente o acompanhamento do pré-natal foi o fato de serem solteiras e não quererem assumir publicamente a gravidez antes que essa se tornasse evidente.

Quanto à assiduidade, identifiquei que a maioria das mulheres estudadas tiveram participação assídua nas consultas agendadas, uma vez que apenas três clientes não compareceram a algum dos retornos previstos nos prontuários. É importante salientar que a própria estrutura do serviço dificultava o não comparecimento aos retornos agendados, visto que a falta aos mesmos acarretaria a necessidade de procurar o serviço (enfrentando longas filas) só para marcar uma nova consulta, que muitas vezes só era conseguido para 20 a 30 dias depois. Além disso, ao se inscreverem no Programa de Assistência Pré-natal as mulheres eram informadas de que se faltassem às consultas, correriam o risco de não mais serem atendidas por falta de vaga.

A maioria das gestantes desenvolvia atividades no lar, uma grande parte delas eram estudantes, e uma pequena parcela era de comerciárias. Além disso, a maioria não havia planejado a gravidez, sendo que este porcentual foi maior entre as solteiras. 
Quadro 1 - Onze domínios relativos às gestantes representando quatro diferentes relações semânticas universais

\begin{tabular}{|c|c|c|}
\hline Domínios & $\begin{array}{l}\text { Relações } \\
\text { Semânticas }\end{array}$ & Categorias/Subcategorias \\
\hline $\begin{array}{l}\text { 01. Características pessoais das } \\
\text { gestantes }\end{array}$ & Atributo & $\begin{array}{l}\text { 1. Idade } \\
\text { 2. Estado civil } \\
\text { 3. Escolaridade } \\
\text { 4. Paridade } \\
\text { 5. Atividade profissional } \\
\text { 6. Planejamento da gravidez } \\
\text { 7. Época do início do pré-natal } \\
\text { 8. Aceitação da gravidez }\end{array}$ \\
\hline 02. Razões para fazer o pré-natal & Racional & $\begin{array}{l}\text { 1. Ligadas à saúde pessoal } \\
\text { 2. Ligadas ao parto } \\
\text { 3. Ligadas à criança }\end{array}$ \\
\hline $\begin{array}{l}\text { 03. Razões para fazer o pré-natal no } \\
\text { serviço em estudo }\end{array}$ & Racional & $\begin{array}{l}\text { 1. Ligadas à questão econômica } \\
\text { 2. Ligadas à qualidade do serviço } \\
\text { 3. Ligadas à criança }\end{array}$ \\
\hline $\begin{array}{l}\text { 04. Razões para gostar do pré-natal no } \\
\text { serviço em estudo }\end{array}$ & Racional & $\begin{array}{l}\text { 1. Ligadas aos serviços prestados } \\
\text { 2. Ligadas à qualidade do serviço } \\
\text { 3. Ligadas aos médicos } \\
\text { 4. Ligadas à organização do serviço }\end{array}$ \\
\hline $\begin{array}{l}\text { 05. Reações das gestantes durante a } \\
\text { assistência pré-natal }\end{array}$ & Inchusão & $\begin{array}{l}\text { Tipos de reações apresentadas } \\
\text { 1. Relata intercorrências ou alterações espontaneamente } \\
\text { 2. Relata intercorrências ou alterações só quando questionada } \\
\text { objetivamente } \\
\text { 3. Procura elucidar dúvidas sobre as alterações que a preocupam } \\
\text { 4. Não procura elucidar dúvidas } \\
\text { 5. Aceita o tratamento prescrito sem questionar nada }\end{array}$ \\
\hline $\begin{array}{l}\text { 06. Razões para iniciar o pré natal } \\
\text { tardiamente }\end{array}$ & Racional & $\begin{array}{l}\text { 1. Ligadas às gestantes } \\
\text { 2. Ligadas ao serviço }\end{array}$ \\
\hline $\begin{array}{l}07 \text {. Percepções das gestantes sobre } \\
\text { características do serviço }\end{array}$ & Meio-Fim & $\begin{array}{l}\text { 1. A rotatividade dos médicos } \\
\text { 2. Assistência prestada por alunos }\end{array}$ \\
\hline $\begin{array}{l}\text { 08. Expectativas das gestantes em } \\
\text { relação à assistência pré-natal }\end{array}$ & Inchısão & 1. Relacionadas com o tipo de assistência \\
\hline $\begin{array}{l}\text { 09. Razóes para selecionar os assuntos } \\
\text { a serem abordados durante a } \\
\text { assistência pré-natal }\end{array}$ & Racional & $\begin{array}{l}\text { 1. Ligadas às gestantes } \\
\text { 2. Ligadas à percepção sobre quem presta a as sistência pré-natal } \\
\text { 3. Ligadas às crenças das gestantes (normal da gravidez) } \\
\text { 4. Ligadas às características do serviço } \\
\text { 5. Ligadas às informações obtidas }\end{array}$ \\
\hline $\begin{array}{l}\text { 10. Sentimentos das gestantes diante a } \\
\text { assistência }\end{array}$ & Inchısão & $\begin{array}{l}\text { Tipos de sentimentos } \\
\text { 1. Medo } \\
\text { 2. Preocupação }\end{array}$ \\
\hline $\begin{array}{l}\text { 11. Perceção das gestantes sobre } \\
\text { alterações/mudanças da gravidez }\end{array}$ & Inchısão & $\begin{array}{l}\text { Tipos de alterações } \\
01 \text {. Alterações fisicas } \\
\text { a) alterações em parte do corpo } \\
\text { b) alterações no peso do corpo } \\
\text { c) alteraços na forma do corpo } \\
\text { 02. Alterações no funcionamento orgânico } \\
\text { 03. Se percebendo } \\
\text { 04. Percebendo as pessoas } \\
\text { 05. Percebendo o periodo gestacional } \\
\text { 06. Percebendo a presença da criança } \\
\text { 07. Imaginando a criança } \\
\text { 08. Tendo ansiedade } \\
\text { 09. Tendo medos } \\
\text { 10. Tendo preocupações }\end{array}$ \\
\hline
\end{tabular}


Ao identificar que razões levaram as gestantes deste estudo a procurarem um serviço de pré-natal (domínio 2), três aspectos se sobressaíram: saúde pessoal, parto e criança, já que as futuras mães justificaram que procuraram o serviço de pré-natal para poderem fazer os exames e tratamentos necessários durante a gravidez; para ficarem mais tranqüilas na hora do parto, sabendo que está tudo bem; para terem um médico certo na hora do parto e para saberem como a criança está, se está se desenvolvendo bem, etc.

Porém, ao investigar as razões que levaram as gestantes freqüentadoras do serviço em estudo a procurá-lo (domínio 3), para fazer o acompanhamento de seu pré-natal, notei três aspectos: econômico, qualidade do serviço e localização geográfica do serviço.

A questão econômica foi facilmente identificada, uma vez que a maioria das mulheres mencionaram não serem beneficiárias do INAMPS. Além disso, ao serem questionadas objetivamente sobre esta questão, elas se referiram com muita frequiência ao fato de que naquele serviço não precisavam pagar para serem atendidas, nem pelos exames solicitados durante a assistência pré-natal, já que até a ultra-sonografia podia ser realizada gratuitamente, desde que solicitada pelo docente responsável pelo atendimento pré-natal.

Com relação à qualidade do serviço, muitas mulheres disseram que estavam fazendo o pré-natal naquele local devido às boas experiências que já tinham tido neste mesmo setor ou em outro e/ou devido às informações positivas obtidas junto a conhecidos ou parentes que já haviam utilizado o serviço, como pode ser observado nas falas que se seguem.

"Apesar de morar em outra cidade, estou fazendo o PN aqui porque minha mãe se trata neste hospital e é muito bem atendida".

"Eu trato meus guris aqui e sou bem atendida, $a d r^{a}$... é muito boa, os meninos gostam muito dela, quando fiquei grávida achei que aqui seria melhor atendida."

"A minha vizinha estava fazendo o pré-natal aqui e me disse que era muito bom...”.

Quanto às razões ligadas à localização geográfica, foi comum o fato de ouvir depoimentos como os seguintes: ônibus”.

"Pra mim aqui é mais fácil, nem preciso pegar

“Aqui é bom porque o ônibus pára na porta".
Quando tentei investigar se as gestantes estavam gostando ou não da assistência que estavam recebendo (domínio 4), tendo em vista que com esta questão seria possível identificar os problemas e as suas possíveis origens, detectei que, de maneira geral, todas as gestantes estavam satisfeitas e as razões apresentadas por elas foram:

\section{a) ligadas aos serviços prestados, e citaram:}

\section{- a realização de exames}

"Gosto daqui porque eles fazem todos os exames que precisam, repete se for o caso, para tratar tudo direitinho".

\section{- a realização de tratamentos}

"Eles tratam tudo que aparece, às vezes a gente até pensa que não é problema, que depois da gravidez vai passar, como a anemia por ex., mas eles fazem questão de tratar tudo direitinho, até ficar tudo bem".

\section{- as orientações oferecidas}

"Eu gosto do pré-natal daqui porque acho que fui bem preparada... recebi orientação sobre alimentação, cuidados necessários na gravidez, etc”.

"O que eu gosto mesmo é porque eles dão orientação de como está o nenê".

- o fato de naquele serviço poderem ouvir o coração no nenê

“... acho legal eles deixarem a gente ouvir o coraçãozinho do nenê”.

b) ligadas à qualidade do serviço, sendo que com relação a este aspecto o argumento mais citado foi o fato de, no serviço, ser realizado um exame físico completo.

"Os outros médicos às vezes nem olham na cara da gente, não examinam nada e já dizem que está tudo bem; aqui não, eles examinam tudo, toda vez que a gente vem na consulta".

"Nos outros médicos eles não examinam a gente como aqui, por isto a gente fica sabendo de problemas que nem imaginava ter, como esta inflamação que vou começar a tratar".

c) ligadas aos médicos, no momento elas se referiram aos acadêmicos, os quais eram os responsáveis pela 
prestação da assistência. Os comentários feitos com relação a este aspecto foram do tipo:

\section{"Os médicos são bons".}

"Os médicos são atenciosos".

"A gente se dá bem com os médicos".

\section{d) ligadas à organização do serviço}

"Eu comecei a fazer meu PN lá no Dasp, mas precisei fazer o exame de urina duas vezes porque eles não acharam o resultado, da segunda vez me enchi e comecei fazer aqui. Na primeira consulta eles já pediram um monte de exames, e depois eu já fiz exames mais duas vezes e eles nunca perderam o resultado. Aqui é tudo mais organizado".

"Aqui é melhor porque a gente chega, espera um pouco e logo é atendida, não precisa ficar no tempo, naquelas filas enormes e em pé esperando a vez que parece que nunca chega, gente furando fila, aqui não... é organizado, a gente chega e eles já anotam pra gente ser chamada logo".

De acordo com as normas do serviço, todas as gestantes deveriam chegar no máximo até às 8 h30 min. para não perder o direito à consulta; estas deveriam ser marcadas com antecedência, o que geralmente era feito no dia da última consulta, e as gestantes eram atendidas de acordo com a ordem de chegada.

Com relação aos tipos de reações ou comportamentos apresentados pelas gestantes durante a assistência pré-natal (domínio 5), identifiquei a existência de pelo menos cinco tipos diferentes de reações. Por exemplo, existem gestantes que (a) relatam intercorrências ou alterações espontaneamente, ou seja, mesmo quando o médico não pergunta. Isto ocorre principalmente se elas apareceram após a última consulta e/ou estejam causando incômodo ou preocupação. Existem aquelas gestantes que (b) só relatam intercorrências ou alterações quando questionadas objetivamente e, mesmo nestes casos o relato pode ser bastante variável, quer dizer, o questionamento tanto pode desencadear a espontaneidade da cliente, a qual passa a dar todas as informações possíveis a respeito da intercorrência ou alteração em questão, como pode não ser suficiente para despertar esta espontaneidade, sendo necessário fazer questionamentos objetivos sobre cada uma das características da alteração.

Algumas gestantes, (c) além de relatarem a presença e as características das intercorrências ou alterações, procuram elucidar junto ao médico todas as dúvidas que têm sobre as mesmas. Outras, no entanto, (d) apesar de relatarem a presença e as características das intercorrências ou alterações que estão experienciando, não procuram elucidar dúvidas, apesar de estarem preocupadas.

Aliás, estes comportamentos também foram observados no momento em que o médico comunicava/ informava o tratamento prescrito, pois enquanto algumas gestantes questionaram e exploraram ao máximo não só a forma de usar o medicamento, mas também sobre o seu efeito, outras, no entanto, (e) aceitaram passivamente o tratamento prescrito, sem questionar nada, mesmo que não tivessem entendido o porquê de usar determinados medicamentos e/ou a forma de usá-los.

Outro fato observado e que está, de certa forma, relacionado com a característica da amostra, é o grande número de clientes que iniciaram tardiamente o acompanhamento de seu pré-natal (domínio 6). Entre as razões apresentadas identifiquei algumas ligadas à gestantes e outras ao serviço.

Entre as ligadas às gestantes constatei por exemplo que, para algumas, o fato de ser solteira constitui uma forte razão para iniciarem tardiamente o acompanhamento do pré-natal. Algumas aliás, só conseguiram iniciar este acompanhamento a partir do momento em que sua situação foi de certa forma "legalizada", seja através do casamento, seja simplesmente pelo fato de ir morar junto com o, até então, namorado. Outra razão bastante citada foi o fato de trabalharem fora, o que foi mais freqüente entre as mulheres que, pelo motivo citado anteriormente, estavam impossibilitadas de assumirem a gravidez. Entretanto, algumas mulheres casadas também fizeram referência ao fato de enfrentarem dificuldades em seu trabalho para comparecerem às consultas de pré-natal, mesmo apresentando aos patrões atestado de comparecimento.

Já com relação às razões ligadas ao serviço, identifiquei que, para as mulheres deste estudo, o fato de a assistência pré-natal ser prestada só no período matutino também concorreu para o estabelecimento de algumas dificuldades, visto que neste período, principalmente para quem trabalha de doméstica, há uma maior concentração de atividades.

Outra dificuldade apresentada foi a de conseguir a primeira consulta no serviço, representada muito mais pelo tempo de espera da consulta do que por uma dificuldade propriamente dita. Este tempo de espera, que em geral variou entre uma semana e um mês, representou para algumas mulheres uma dificuldade pois, ao procurarem o serviço pela primeira vez, esperavam que fossem atendidas no mesmo dia, o que até ocorreu para algumas, conforme observei.

No que se refere às características do serviço (domínio 7) as gestantes fizeram referência apenas a duas 
questões: o fato de não ser o mesmo médico responsável pela assistência em todas as consultas, e o fato de o atendimento médico ser prestado por alunos. O primeiro fato é consequência do segundo. De maneira geral, as mulheres aceitavam esta rotatividade, porém ao entrar no mérito da questão, elas costumavam dizer que a mudança de médico a cada consulta, de certa forma, dificultava a manifestação das alterações por elas percebidas, como pode ser observado no exemplo que se segue.

"Eu não vou ficar repetindo tudo o que acontece cada vez que venho aqui; se fosse o mesmo médico não ia precisar ... ele sempre ia lembrar de alguma coisa".

Em contrapartida, houve alguns comentários que, apesar de não ser possível identificar a real razão, foram favoráveis à rotatividade de quem prestava a assistência.

"Eu acho bom cada mês ser um médico, por ser mais prático”.

Já com relação ao fato de o atendimento médico ser prestado por alunos, identifiquei três tipos de reações.

Houve gestantes que afirmaram textualmente serem favoráveis a este tipo de atendimento:

"Acho que ser atendida por aluno é até melhor do que por formado, pois o aluno tem mais interesse".

Outras eram desfavoráveis:

"Não gosto de aprendiz, eles não sabem de nada”.

"Os aprendizes só sabem ver e medir a barriga, perguntam pra gente de quantos meses a gente está e depois falam o que eles acham pela conta deles".

E outras, ainda, eram indiferentes:

"Não me incomodo de ser atendida por alunos".

Quanto às expectativas das gestantes com relação à assistência pré-natal (domínio 8), identifiquei quatro espécies:

a) as relacionadas com a "assistência", que englobam os tipos de serviços prestados pela instituição como um todo

"Eu acho incrível que um serviço como este não tenha maternidade, de que adianta fazer o PN aqui?".

"A gente espera que, fazendo o PN aqui, todos os exames necessários também sejam feitos, que a gente possa ficar tranqüila, sem precisar ficar andando de um lado para outro, conseguindo um exame aqui, outro ali, etc".

Como pode ser notado, embora o serviço apresentasse como vantagem o fato de realizar todos os exames necessários gratuitamente, inclusive a ultrasonografia, que na época era a maior dificuldade para conseguir, devido ao número restrito de exames que podiam ser realizados por mês no Inamps, ele tinha como inconveniente o fato de não possuir uma maternidade $\mathrm{e}$ isto constituía ponto de preocupação para as mulheres que, como visto anteriormente, realizam o pré-natal com o intuito de ter um médico certo na hora do parto.

\section{b) as relacionadas com os tipos de orientações que} gostariam de receber

"Acho que no pré-natal as mulheres deveriam ser orientadas sobre os exercícios que podem ou devem fazer".

"Acho que no pré-natal poderiam falar sobre sinais do parto, como cuidar da criança, de sua alimentação e até como amamentar".

“Eu gostaria de ser orientada sobre como é ganhar nenê".

Destas falas, depreende-se que as expectativas que as mulheres conseguiram expressar explicitamente quanto às orientações que gostariam de receber relacionam-se com o estado de gravidez (fisiológico); no entanto, constatei que, durante nossas conversas (entrevistas), elas expressavam muitos outros aspectos que nem de longe eram abordados durante algumas das atividades no serviço, nem mesmo com a enfermeira, embora com esta elas conseguissem abordar outros aspectos, não só os relacionados com as alterações na forma do corpo.

c) as relacionadas com o tipo de relacionamento mantido com os profissionais de saúde, mais especificamente com os médicos

"Em casa eu lembro de uma porção de coisas que gostaria de saber, mas chega aqui, conforme quem vai atender a gente, eu não tenho coragem de perguntar nada. Acho que os médicos tinham que ser mais amigos e compreender mais os problemas da gente". 
d) as relacionadas com a conduta dos médicos

"Acho que é função dos médicos falarem tudo o que ocorre durante a gravidez, até coisas que possam vir a acontecer".

"Eu gostaria que os médicos explicassem um pouco mais as coisas para a gente, não só falar você tem isto e vai fazer isto e isto. Assim, sem nem se importar se a gente está preocupada ou não e se a gente entendeu ou não".

Finalmente, um dos domínios identificados com maior freqüência durante todo o período no campo foi o fato de as gestantes fazerem uma espécie de seleção sobre o que falar e com quem falar sobre determinadas percepções. Quando tentei identificar as razões que levavam as gestantes a selecionarem, em seus relatos ao médico, os tipos de alterações ou intercorrências que percebiam durante a gravidez (domínio 9), constatei a presença de cinco diferentes razões.

a) Razões ligadas às características das gestantes, como por exemplo, o fato de ela ser inibida ou tímida, e aquelas que surgiram em decorrência da assistência prestada. Por exemplo, foi comum o fato de as mulheres revelarem que não manifestaram verbalmente suas percepções de alterações ou intercorrências ao médico e nem mesmo à enfermeira por:

\section{- medo de levar bronca}

"Quando eu estava de três meses, caí e machuquei a costela, acho que trincou, até hoje dói quando respiro mais fundo, mas eu tenho medo de falar para o médico e ele ficar bravo por eu não ter contado antes".

\section{- medo de sentir dor}

"Às vezes eu não reclamo de nada para ver se eles não mexem muito, porque às vezes eles mexem tanto, apertam tanto para ver a posição do nenê, que fico toda doída”.

\section{- medo do diagnóstico}

"Dos disparos no coração eu não falo pro médico não... tenho medo de ser alguma coisa ruim".

\section{- falta de coragem/insegurança}

"Quando tem alguém do lado, alguém que fique na sala com a gente, para dar um apoio, é mais fácil a gente falar as coisas, senão fico sem muita coragem de abrir a boca, só falo o que ele pergunta”.

\section{- medo da conduta}

"Eu queria falar que não consigo dormir à noite, mas tenho medo que eles receitem algum tranqüilizante e faça mal à criança”.

\section{- esquecimento} esqueci”.

"Eu sempre falo tudo, quando não falo é porque

"Às vezes, quando chego em casa é que vou lembrar de alguma coisa que queria perguntar ou contar".

\section{- por priorizar determinados tipos de problemas}

"Eu nunca falei nada que não fosse doença, não porque não tenha problemas, mas porque acho que tem outros problemas que são mais importantes".

b) Razões ligadas à percepção que as gestantes tinham sobre quem prestava a assistência, isto porque foi comum usarem as seguintes justificativas:

\section{- achar que não resolveriam/fariam alguma coisa}

"Não adianta falar, porque eles não dizem nada, fica só por falar".

\section{- achar que não saberiam o que fazer}

"Da última vez que eu vim aqui o médico que me atendeu era todo atrapalhado, inseguro mesmo, então não falei nada porque achei que ele não ia saber o que fazer".

\section{- achar que não querem falar}

"Eu não tenho coragem de perguntar porque acho que eles não querem falar, porque eles sabem que a gente vem para ser orientada, se não falam é porque não querem falar".

\section{- achar que não querem saber sobre certas coisas}

"Tem algumas coisas que a gente fala e eles não querem nem saber.. nem deixam a gente terminar e já perguntam sobre outra coisa, o tempo de gravidez mesmo, perguntam sempre". 


\section{- o tipo de conduta não satisfaz}

"Da outra vez que eu vim eu falei sobre a volta e aumento das varizes e a médica só disse 'isto é fogo' e este tipo de resposta não me ajudou em nada, só me deixou mais preocupada".

"Os médicos só conversam com a gente aquilo que a gente sente em termos de dor e também só dor pelo lado de fora, nada que envolva os órgãos sexuais por exemplo".

Como neste serviço a assistência é prestada por estudantes de medicina, concluímos, pelas razões apresentadas pelas gestantes e relacionadas com as pessoas que prestavam a assistência, que está havendo uma formação inadequada dos profissionais de saúde, os quais não estão sendo preparados para dar maior atenção às percepções e queixas dos clientes. Este tipo de conduta e o fato de priorizarem a sua satisfação pessoal e não a do cliente que o procurou, em última instância, representa uma falta de respeito dos profissionais para com a clientela.

c) Razões ligadas às crenças (às vezes erradas) das gestantes

"Acho que já estou com anemia, mas não falei nada para o médico, porque acho que é normal, que toda mulher grávida fica com anemia”.

\section{d) Razões ligadas às características do serviço}

"Não dá para falar para o médico sobre os meus temores, porque cada vez que venho aqui é um médico diferente e eu não vou ficar repetindo sempre a mesma coisa”.

\section{e) Razões ligadas às informações obtidas anteriormente}

"Quando eu vim fazer o pré-natal aqui eu já sabia que tem algumas coisas que não adianta falar porque eles não fazem nada a respeito, minha cunhada fez o pré-natal aqui”.

Como se evidencia nesta fala, na hora de escolher onde realizar o pré-natal, este serviço é preterido em relação aos demais, apesar das mulheres conhecerem algumas de suas limitações, o que denota a confiabilidade no serviço.

Com relação aos sentimentos das gestantes diante da assistência pré-natal (domínio 10), identifiquei a existência de medos e preocupações. O medo reflete, até certo ponto, o estado de insegurança das gestantes, proveniente, provavelmente, de insuficientes orientações relacionadas com o trabalho de parto durante a assistência pré-natal, como pode ser percebido nas falas que se seguem.

"Eu fico com medo de deixar passar a hora”.

"E se a gente não souber certo quando é a hora, o que pode acontecer?".

"Eu morro de medo de nascer em casa (riso) eu não vou saber o que fazer".

"Tenho medo de não saber que é o trabalho de parto...”.

Já as preocupações com a assistência recebida foram manifestadas de forma direta, em relação:

\section{- à qualidade do atendimento}

"Eu não sei... às vezes penso que seria melhor se o médico mesmo visse a gente. Fico preocupada... e se eles (doutorandos) ainda não sabem as coisas direito".

\section{- ao uso de termos científicos/não conhecidos}

"Quando eles ficam conversando entre eles na minha frente, fico preocupada, não sei sobre o que eles estão falando, fico pensando que alguma coisa não está bem".

\section{- ao tipo de atendimento}

“... eu me preocupo com isto, gostaria de não ter um atendimento tão impessoal”.

\section{- às orientações não recebidas}

"Acho que no pré-natal a gente deveria ser orientada sobre tudo, inclusive o que pode mudar de um mês para outro... principalmente prá gente que é a primeira vez, às vezes acontece alguma coisa, eu fico superpreocupada, nervosa até... e quando chega no dia da consulta eles dizem: ' não precisa se preocupar com isto, é normal da gravidez principalmente nesta fase que você está...' por que não falaram antes que podia acontecer... evitava o nervoso".

Esta fala demonstra como a evolução da gravidez tem sido tratada no serviço em estudo, ou seja, todos os problemas/intercorrências apresentadas são interpretadas como "normais" da gravidez, o que denota que há uma generalização dos sintomas sem se levar em consideração 
aspectos individuais de cada mulher e de cada experiência de gravidez.

\section{- à ausência de explicações sobre a evolução da gravidez}

"Eu não sei nada de gravidez e fico preocupada com isto... a gente nunca sabe direito o que é ou não normal, eles aqui falam que tudo é normal, mas até que ponto é mesmo, porque eu sinto esta dor no pé da barriga e a minha cunhada não sentiu. Eu queria saber o porquê da dor e não só que é normal”.

"Acho que é a maior falta de consideração eles olharem os resultados dos exames e só falarem que está tudo bem, sem explicar mais nada, acho que é porque a gente não paga, mas a gente deveria ter direito de saber ao certo das coisas que acontecem com a gente".

Com relação às percepções das mulheres durante o período gestacional, observei que, à medida que a gestação avança, elas percebem diferentes mudanças em si, nos outros e nas suas vidas de modo geral. Observei também que elas fazem distinções entre os diferentes tipos de mudanças/alterações, de forma que, para as gestantes, elas podem ser identificadas como sendo alterações normais, esperadas, desejadas, inesperadas, indesejadas, etc. Além disso, na hora em que elas fazem esta "classificação", constatei que utilizam alguns parâmetros, já que o mesmo tipo de alteração em mulheres diferentes, e até numa mesma mulher, pode ser identificado/classificado de forma diferente, dependendo da época de seu surgimento, de sua intensidade, de suas características, etc.

Constatei ainda que esta classificação, de certo modo, influencia o relato sobre a forma como elas percebem as mudanças/alterações/intercorrências que experienciam durante a gravidez, tornando possível que as mesmas sejam classificadas como alterações facilmente relatadas ou não.

Em comunicação posterior, pretendo apresentar a relação de todas as alterações e intercorrências percebidas pelas mulheres deste estudo, bem como o que consegui captar sobre a forma como percebem as alterações e intercorrências da gravidez, exemplificadas por suas próprias falas. Ressalte-se que, a despeito das inúmeras alterações percebidas pelas mulheres, só as físicas e algumas no funcionamento orgânico são facilmente relatadas e mesmo abordadas pela equipe de saúde.

\section{CONCLUSÕES E CONSIDERAÇÕES FINAIS}

Por se tratar de uma análise secundária, o estudo apresenta como principal limitação o fato de os informantes não terem sido questionados nem convidados a esclarecer aspectos obscuros; por outro lado, ele tem valor na medida em que todos os aspectos levantados foram abordados pelas gestantes espontaneamente, ou seja, ao relatarem como estavam vivenciando a experiência de uma gravidez, elas abordaram aspectos da assistência que estavam recebendo.

Desta forma, os resultados encontrados permitenos concluir que as representações que as mulheres fazem de suas expectativas em relação a um serviço de pré-natal podem relacionar-se tanto a um contexto mais amplo, que diz respeito às expectativas em relação a qualquer serviço de pré-natal, como a um contexto mais restritivo, que é a assistência pré-natal prestada no serviço onde foi realizado o estudo (uma assistência centrada no profissional médico e permeada pelas características de um serviço utilizado como campo de estágio para estudantes de medicina).

As expectativas das mulheres identificadas neste estudo em relação a um serviço de pré-natal são:

- que a instituição seja capaz de prestar assistência gratuita não só durante o pré-natal mas também por ocasião do parto e do puerpério;

- que na assistência prestada esteja incluida a realização gratuita de exames laboratoriais e ultrasonográficos;

- que durante a assistência pré-natal sejam realizadas orientações relacionadas: ao desenvolvimento da gravidez, ao trabalho de parto, aos cuidados necessários durante a gravidez e os cuidados com o recém-nascido; - que o docente esteja mais presente e acompanhe de perto o trabalho dos estudantes de medicina;

- que não haja tanta rotatividade dos estudantes de medicina;

- que o parto seja realizado pelo mesmo médico (estudante) que faz o pré-natal;

- que o atendimento não seja tão impessoal;

- que seja dada maior atenção às suas percepções e queixas;

- que os profissionais de saúde (especialmente os médicos) se mostrem mais atenciosos e interessados na experiência que está sendo vivenciada por cada mulher individualmente;

- que os profissionais de saúde se preocupem em identificar e diminuir ansiedades, medos e preocupações experienciadas pelas gestantes;

- que os profissionais de saúde não façam uso de tantos termos técnicos, especialmente sem explicá-los.

Além disso, os aspectos identificados neste estudo exploratório demonstram que, ao se relacionarem com profissionais de saúde, as gestantes filtram 
informações (só relatam determinados tipos de problemas experienciados) ao mesmo tempo que se apresentam como clientes não-participativas, uma vez que não questionam a assistência que lhes é prestada, mesmo quando esta não atende às suas expectativas. Além disso, apesar de as mulheres considerarem que a assistência prestada no serviço em estudo é melhor do que a prestada em outros serviços, esta assistência não consegue, segundo as próprias gestantes, atender às suas expectativas e necessidades reais.

Portanto, ao que parece, a assistência pré-natal que tem sido prestada neste serviço tem se preocupado muito mais com a gravidez do que com a "mulher grávida".

Assim, o fato de as mulheres poderem fazer uma série de exames diagnósticos gratuitamente e sem muita burocracia constitui um aspecto positivo nos hospitais utilizados como campo de ensino, mas para conseguir isto elas precisam se submeter a uma assistência que não lhes dá a segurança desejada no transcorrer de sua gravidez, devido principalmente à troca de médico a cada reconsulta. No serviço em questão, como não existe o setor de maternidade, esta insegurança também é reforçada pelo fato de a gestante nem ter um médico certo na hora do parto, razão identificada como relevante para o início do acompanhamento do pré-natal.

Estes aspectos nos levam a considerar que a procura por este serviço, sem dúvida, ocorre por parte só das mulheres grávidas que não possuem condições socioeconômicas que lhes possibilitem procurar um outro tipo de assistência. Isto é preocupante pois neste serviço estão sendo formados novos profissionais, e mesmo assim, não está sendo dada a devida atenção aos aspectos psicológicos, antropológicos e sociais, de forma a subsidiar uma atuação junto a mulheres grávidas, de forma global e individualizada, o que sem dúvida tende a comprometer a assistência a ser prestada pelos mesmos em um futuro próximo.

\section{FLASHES OF HOW PREGNANTS PERCEIVE PRE-NATAL CARE IN A UNIVERSITY HOSPITAL}

This article was based on a research carried out to characterise the pre-natal care offered to pregnant women at the out patient unit of a university hospital. This qualitative study used Ethnography, more precisely Miniethnography. The methodological approach and data collection were done through Participating Observation. Results showed that pregnant in touch with health professionals are able to filter information and, at the same time, behave as non participating clients, since they do not question the care offered to them even if the care is not good. Although women think that the care offered at this hospital is better than the one offered elsewhere, they admit that it does not respond successfully to their real expectations and needs. Generally speaking, they would like to receive more orientation and more personal assistance. They do not like this care very much mainly because of student's rotativity.

KEY WORDS: pre-natal care, university hospital, qualitative approach

\section{“FLASHES” DE CÓMO LAS EMBARAZADAS PERCIBEN LA ASISTENCIA PRE-NATAL EN UN HOSPITAL UNIVERSITARIO}

Este artículo fue extraído de un estudio desarrollado con el objetivo de comprender y caracterizar la asistencia prenatal dada a la embarazada en el ambulatório de un hospital universitário (MARCON, 1990). Se trata de un estudio cualitativo que adoptó como línea metodológica básica la Etnografía, más específicamente, la Minietnografía y como método de colecta de datos la Observación-Participante. Los resultados demuenstran que, cuando se relacionan con profesionales de la salud, las embarazadas filtran informaciones, al mismo tiempo que se presentan como una cliente no participativa, una vez que no cuestionan la asistencia que le es dada, inclusive cuando ésta no atiende sus expectativas. Por otro lado, apesar que las mujeres consideran que la asitencia recibida en el local de estudio es mejor que la recibida en otro locales, ella no atiende, segun las propias embarazadas, sus expectativas y necesidades reales. En general, las embarazadas desearían obtener más orientaciones y una asistencia menos impersonal. Los motivos por los cuales no les gusta mucho la asistencia estan relacionados, principalmente, con la rotatividad de los alumnos. 


\section{REFERÊNCIAS BIBLIOGRÁFICAS}

01. ADRIAZOLA, D. G. et al. Influência del control prenatal sobre la morbimortalidad materna y perinatal. Bol. Of. Sanit. Panam., Washington, v. 83, n. 5, p. 413-23, 1987.

02. ALMEIDA, M. C. P; VINHA, V. H. P. A motivação na educação em saúde para gestantes. Rev. Bras. Enfermagem, Rio de Janeiro, v. 25, n. 5, p. 93104, 1972.

03. BELIZÁN, J. M et al. Asistencia de embarazadas a la consulta prenatal en maternidades publicas de Rosario, Argentina. Bol. Of. Sanit. Panam., Washington, v.86, n.2, p.121-8, 1979.

04. BONADIO, I. C. Ser tratada como gente: a vivência de mulheres atendidas no serviço de pré-natal de uma instituição filantrópica. São Paulo, 1996. 200p. Tese (Doutorado em Enfermagem). Universidade de São Paulo.

05. CANDEIAS, N. M. F. Assistência pré-natal: conhecimentos, atitudes e práticas de mulheres internadas no serviço de obstetrícia de São Paulo. Rev. Saúde Pública, São Paulo, v. 14, n. 4, p. 428- 38, 1980.

06. CIARI, C. et al. Avaliação quantitativa de serviços de pré-natal. Rev. Saúde Pública, São Paulo, v. 6, n. 3, p. 361-70, 1972.

07. CORTEGUERA, R. H. et al. Avances en pediatria y atención infantil en Cuba (1959-1974). Bol. Of Sanit. Panam., Washington, v. 80, n. 3, p. 187204, 1976.

08. EIRAS, M. S. A gravidez como etapa do desenvolvimento da mulher: relatos de grávidas sobre suas experiências e sentimentos ligados à parentalidade. Campinas, 1983. 80p. Dissertação (Mestrado) - Pontifícia Universidade Católica de Campinas.

09. EVORA, Y. D. M. Orientações ministradas à gestante durante a assistência pré-natal: atuação dos profissionais de enfermagem. Rev. Esc. Enfermagem USP, São Paulo, v. 22, n. 3, p. 33951, 1988.

10. FREDDI, W. E. S. Preparo da gestante para o parto. Rev. Bras. Enfermagem, Rio de Janeiro, v. 26, n. 3, p. 108-20, 1973.
11. GARCIA, T. R. Representações de gestantes adolescentes solteiras sobre aspectos de sua problemática psicossocial: implicações para a enfermagem obstétrica. Rev. Bras. Enfermagem, Brasília, v. 38, n. 3/4, p .281-8, 1985.

12. LEININGER, M. M. Qualitative research methods in nursing. Orlando: Grune \& Stratton, 1985. 361 p.

13. LESSA, I. Avaliação qualitativa de programas prénatais: uma proposição metodológica. Rev. Baiana Saúde Pública, Salvador, v. 3, n. 1/2, p. 1-8, 1976.

14. LOFLAND, J. Analyzing social setting: a guide to qualitative observation and analysis. Belmont: Wadsworth Publishing, 1971.

15. MARCON, S. S. Vivenciando a gravidez. Florianópolis, 1989. 383p. Dissertação (Mestrado em Enfermagem) - Universidade Federal de Santa Catarina.

16. MARCON, S. S. A assistência pré-natal: um estudo etnográfico. Rio de Janeiro, 1990. 272p. Tese (Livre Docência) - Universidade do Rio de Janeiro.

17. NASCIMENTO, M. G. P. Interesses e preocupações a respeito do parto. São Paulo, 1984. 150p. Dissertação (Mestrado em Enfermagem) - Escola Paulista de Medicina.

18. PAIM, J. S. et al. Utilização dos serviços de saúde materna em uma área urbana de Salvador. Rev. Baiana de Saúde Pública, Salvador, v. 3, n. 3/4, p. 48-54, 1976.

19. PARSE. R. R. et al. Nursing research: qualitative methods. Maryland: Brady Communication Company, 1985. 207p.

20. PEARSALL, M. Participant observation as role as method in behavioral reserch. Nurs. Res., New York, v. 14, n. 1, p. 37-42, 1965.

21. PELÁ, N. S. R. Contribuição ao estudo da assistência pré-natal em um município paulista. Bol. Of. Sanit. Panam., Washington, v.86, n.1, p.46- 53, 1979.

22. SILVA, S. A importância do pé-natal no incentivo do aleitamento materno. Rev. Ciencias da Saúde, Florianópolis, v. 7/8, n. 1/2, p. 197-217, 1988.

23. SPRADLEY, J. P. The etnographic interview. New York: Rinehart \& Winston, 1979. 192p. 